\title{
Schistosomiasis differentially affects vasoconstrictor responses: up-regulation of 5-HT receptor-mediated aorta contraction
}

\author{
Suellen D'Arc dos Santos Oliveira, Claudia Lucia Martins Silva/ ${ }^{+}$ \\ Laboratório de Farmacologia Bioquímica e Molecular, Instituto de Ciências Biomédicas, \\ Universidade Federal do Rio de Janeiro, Rio de Janeiro, RJ, Brasil
}

\begin{abstract}
Schistosomiasis, classified by the World Health Organization as a neglected tropical disease, is an intravascular parasitic disease associated to a chronic inflammatory state. Evidence implicating inflammation in vascular dysfunction continues to mount, which, broadly defined, reflects a failure in the control of intracellular $\mathrm{Ca}^{2+}$ and consequent$l y$, vascular contraction. Therefore, we measured aorta contraction induced by 5-hydroxytryptamine (5-HT) and endothelin-1 (ET-1), two important regulators of vascular contraction. Isometric aortic contractions were determined in control and Schistosoma mansoni-infected mice. In the infected animals, 5-HT induced a 50\% higher contraction in relation to controls and we also observed an increased contraction in response to $\mathrm{Ca}^{2+}$ mobilisation from sarcoplasmic reticulum. Nevertheless, Rho kinase inhibition reduced the contraction in response to 5-HT equally in both groups, discarding an increase of the contractile machinery sensitivity to $\mathrm{Ca}^{2+}$. Furthermore, no alteration was observed for contractions induced by ET-1 in both groups. Our data suggest that an immune-vascular interaction occurs in schistosomiasis, altering vascular contraction outside the mesenteric portal system. More importantly, it affects distinct intracellular signalling involved in aorta contraction, in this case increasing 5-HT receptor signalling.
\end{abstract}

Key words: vascular - schistosomiasis - nitric oxide - Rho kinase - 5-HT - immune-vascular

Schistosomiasis is an intravascular parasitic disease characterised by chronic and systemic inflammation. After skin penetration, schistosomes migrate to the host hepatic portal system (Wilson \& Coulson 1986). Adult Schistosoma mansoni worms reside in the mesenteric veins for years where they lay eggs and release antigens, which eventually lead to death (Cutts \& Wilson 1997, Cheever et al. 2002, Wynn et al. 2004).

Previous studies using mouse models and studies in humans have characterised two polarised cytokine profiles observed after infection, namely an early type-1 (Th1) evolving to a type-2 (Th2) T-cell associated cytokine response. Therefore, the secretion of these cytokines depends on the phase of infection; cytokines, such as tumour necrosis factor (TNF; Th1), interleukin (IL)-4, IL-5 and IL-13 (Th2), are expressed during infection (Wynn et al. 2004). The balance between the effects of pro and anti-inflammatory cytokines is thought to determine disease outcome (Wynn et al. 2004, Caldas et al. 2008). Reinforcing the systemic inflammatory characteristic of schistosomiasis, a state of hypereosinophilia is established after infection, which is related to endomyocardial fibrosis, pulmonary hypertension and portal vein infiltration (Silva et al. 1998, Franco-Paredes et al. 2007).

Besides mediating inflammatory processes, cytokines may modulate vascular function. In fact, previous studies have shown that some cytokines that are secreted in schistosomiasis also modulate vascular functions. For in-

Financial support: CNPq (472952/2007-2, 472474/2010-3), FAPERJ

+ Corresponding author: cmartins@farmaco.ufrj.br

Received 14 December 2010

Accepted 3 May 2011 stance, IL-13, a cytokine produced by both Th and non-T cells, including eosinophils, increases the expression of 5-hydroxytryptamine $(5-\mathrm{HT})_{2 \mathrm{~A}}$ receptors and smooth muscle contractility (Zhao et al. 2006). Furthermore, TNF has been linked in other models to an enhanced vasoconstriction response and to a reduced expression of endothelial nitric oxide synthase (eNOS), resulting in the reduction in nitric oxide (NO) bioavailability (reviewed in Vila \& Salaices 2005, Sprague \& Khalil 2009, Zhang et al. 2009). Schistosomiasis increases portal vein contraction in response to 5-HT and acetylcholine (Silva et al. 2003) and reduces endothelium-dependent NO-mediated vasodilatation (Silva et al. 1998) and eNOS expression (unpublished observations). Similar results were observed on aortic constriction in male S. mansoni-infected mice (Silva et al. 2007), i.e., in the absence of eggs when exposed to the vasoconstrictor noradrenaline, an effector of the sympathetic autonomous system.

Vascular lesions outside the mesenteric portal system are observed in pulmonary artery hypertension, which is typically linked to the presence of eggs in the lung that pass through the porto-systemic shunts (Franco-Paredes et al. 2007, reviewed in Kolosionek et al. 2010) and cytokine production (Crosby et al. 2010). However, the lack of eggs in the aorta reinforces the hypothesis that circulating egg- and worm-derived antigens and host-derived cytokines affect the vascular system.

In recent years, 5-HT and endothelin 1 (ET-1) have been recognised as important mediators in vascular physiology and are now implicated in vascular disease resulting from chronic inflammation (Eddahibi et al. 2006, Iglarz \& Clozel 2007). Our study examined the effects of 5-HT and ET-1 on aorta reactivity in S. mansoni-infected mice, focusing on intracellular signalling pathways involved in vascular contraction. 


\section{MATERIALS AND METHODS}

Animals and ethics - Male Swiss mice (75-90 days old) were used in all procedures. All experiments were carried out in compliance with ethical standards of our institution (Ethics Committee of the Federal University of Rio de Janeiro the recommendations of the National Council on Experimental Animal Control) and were licensed (DFBC-ICB-011).

Animals were housed under a $12 / 12 \mathrm{~h}$ light/dark cycle and had access to water and food ad libitum. We sought to minimise animal suffering and the minimum number of animals necessary for valid statistical evaluation was used.

Animals were infected as previously described (Lenzi et al. 2006). Briefly, mice (7 days old) were infected by percutaneous exposure to 80 cercariae of both genders (BH strain; obtained from infected Biomphalaria glabrata snails) for $8 \mathrm{~min}$.

Isometric tension assays - Infected (75-90 days after infection) and age-matched control mice were anesthetised and sacrificed by cervical dislocation. The abdomen was surgically opened and the thoracic aorta was carefully removed, dissected and cut into $3 \mathrm{~mm}$ rings. The aortic rings were fixed to an isometric tension transducer, immersed in an organ bath filled with physiological saline solution (PSS) $(122 \mathrm{mM} \mathrm{NaCl}, 5 \mathrm{mM} \mathrm{KCl}$, $15 \mathrm{mM} \mathrm{NaHCO}, 11.5 \mathrm{mM}$ glucose, $1.25 \mathrm{mM} \mathrm{MgCl}$, $1.25 \mathrm{mM} \mathrm{CaCl}_{2}$ and $\left.1.25 \mathrm{mM} \mathrm{KH}_{2} \mathrm{PO}_{4}\right)$ and aerated with oxygen and carbon dioxide $\left(95 \%{ }^{2} \mathrm{O}_{2}: 5 \% \mathrm{CO}_{2}\right)$ at $37^{\circ} \mathrm{C}$. Aortic rings were stretched to an optimal tension of $10 \mathrm{mN}$ and then were equilibrated for $60 \mathrm{~min}$. After the stabilisation period, KCl-induced contraction was performed using a PSS solution in which $\mathrm{NaCl}$ was isotonically replaced with $100 \mathrm{mM} \mathrm{KCl}$. The tissues were washed three times with PSS and allowed to recover for further $60 \mathrm{~min}$. Ring contractions were then induced by the addition of 5-HT $\left(10^{-9}-10^{-5} \mathrm{M}\right), 32 \mathrm{mM}$ caffeine [in this case, the preparation was incubated in $\mathrm{Ca}^{2+}$-free medium containing $0.1 \mathrm{mM}$ ethylene glycol tetraacetic acid (EGTA)] or $100 \mathrm{nM}$ ET-1. The contractions were performed in the presence of $250 \mu \mathrm{M}$ $N^{\omega}$-nitro-L-arginine (L-NNA) (NOS inhibitor) before and after the treatment $(30 \mathrm{~min})$ with $5 \mu \mathrm{M}$ Y-27632 (Rho kinase inhibitor). The concentration of Y-27632 $(5 \mu \mathrm{M})$ was determined in preliminary assays and is routinely mentioned in the literature.

The force generated expressed as $\mathrm{mN}$ units was isometrically recorded using a Grass transducer (FT-03) connected to a data acquisition system (MacLab, Inc, USA) and further quantified using Chart 3.4/s software (MacLab, Inc, USA) (Silva et al. 2003). The experiments were performed with one or two rings obtained from eight-10 animals.

Statistical analysis - Graphical data are presented as mean and standard error of the mean (SEM) of the indicated number of observations (i.e., number of rings). The maximal contraction in response to agonist $\left(E_{\max }\right)$ and the concentration that elicits $50 \%$ of the maximal response $\left(E C_{50}\right)$ were individually estimated by non-linear regression (Silva et al. 2007). These data are expressed as mean \pm SEM. Paired or unpaired Student's $t$ tests were performed considering the arithmetic means from $\mathrm{n}$ individual experiments and $\mathrm{p}<0.05$ (GraphPad Prism 5, GraphPad Software, San Diego California USA, www. graphpad.com).

Drugs - L-NNA, 5-HT and EGTA were purchased from SIGMA Chemical Co (St. Louis, MO, USA); ET-1 was purchased from Tocris Bioscience (Ellisville, USA) and Y-27632 from Merck (USA). Stock solutions were prepared in deionised water (Y-27632, 5-HT $10 \mathrm{mM}$ ), NaOH $0.05 \mathrm{mM}$ (L-NNA $25 \mathrm{mM}$ ), 100\% dimethylsulphoxide (ET-1 $10 \mathrm{mM}$ ) and diluted daily in buffered physiological solution. Caffeine $(32 \mathrm{mM})$ was diluted in $\mathrm{Ca}^{2+}$-free PSS. The highest final concentration of the solvent was $0.1 \%$ $(\mathrm{v} / \mathrm{v})$ and had no effect on the experiments.

\section{RESULTS}

Aortic contraction induced by 5-HT and ET-1 - 5-HT induced a concentration-dependent response in aorta from both control and infected groups (Fig. 1). However, the contractions induced by several 5-HT concentrations (30-10,000 nM) were significantly higher in the infected than in the control mice. As a result the $E_{\max }$ induced by 5 -HT was greater in the infected $(16.46 \pm 0.65 \mathrm{mN} ; \mathrm{n}=$ 11) than in the control group $(11.35 \pm 1.04 \mathrm{mN}, \mathrm{n}=9, \mathrm{p}$ $<0.05$ ). On the other hand, the potency of 5-HT did not change as revealed by the similar $E C_{50}$ values between groups that were in the $\mathrm{nM}$ range of concentration [ $\log$ of $E C_{50}:-7.2 \pm 0.07$ and $-7.2 \pm 0.05 \mathrm{M}$, for control $(\mathrm{n}=9)$ and infected $(n=11)$, respectively].

Differently from the contraction induced by 5 -HT, ET-1 induced a non-sustainable contraction in mice aorta with maximal effect attained at $10 \mathrm{nM}$. The developed force in response to this concentration represented near $100 \%$ of the contraction induced by $\mathrm{KCl} 100 \mathrm{mM}$ in both groups of animals, which is in agreement with previous data (Zhou et al. 2004). However, differently from what was observed with 5-HT in this model, there was no difference in aorta contraction in response to ET-1 between the two groups $(5.88 \pm 0.45$ and $5.19 \pm 0.61 \mathrm{mN}, \mathrm{n}=10$, control and infected mice, respectively).

Intracellular pathways involved in the enhanced. 5-HT-induced vascular contraction in S. mansoniinfected mouse - A key event for 5-HT-induced aorta contraction is the increase of intracellular $\mathrm{Ca}^{2+}$ mediated

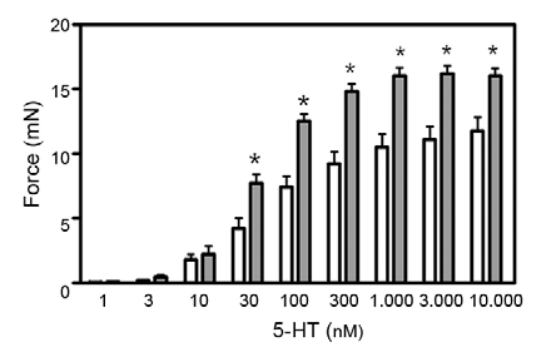

Fig. 1: contraction of aorta from control (white bars) and Schistosoma mansoni-infected (gray bars) mice induced by 5 -hydroxytryptamine (5-HT) in the presence of $N^{\omega}$-nitro-L-arginine $250 \mu \mathrm{M}$. Data are expressed as the mean and standard error of the mean $(n=10$ rings). Asterisk means $\mathrm{p}<0.05$ (Student's $t$ test). 
both by $\mathrm{Ca}^{2+}$ influx and by mobilisation from sarcoplasmic reticulum (Low et al. 1997, McKune \& Watts 2001). As shown in Fig. 2, caffeine ( $32 \mathrm{mM}$ ), a pharmacological tool that mobilises $\mathrm{Ca}^{2+}$ from sarcoplasmic reticulum, induced a greater contraction in aortic rings in the infected as compared to control group.

Rho kinase activity regulates $\mathrm{Ca}^{2+}$ sensitivity of the vascular contractile machinery (Somlyo \& Somlyo 2003). The selective inhibition of Rho kinase in vitro reduced the contraction induced by 5-HT in both groups (Fig. 3, Table I). However, despite the fact that the remaining force after Rho kinase inhibition was still higher in the infected group than in the control group (Table I), the mean absolute reduction of the developed force was similar in both groups (about $7 \mathrm{mN}$ ).

In addition, we also investigated this intracellular signalling in the contraction induced by ET-1. Rho kinase inhibition abolished the contraction in response to ET-1 similarly in both groups (Table II).

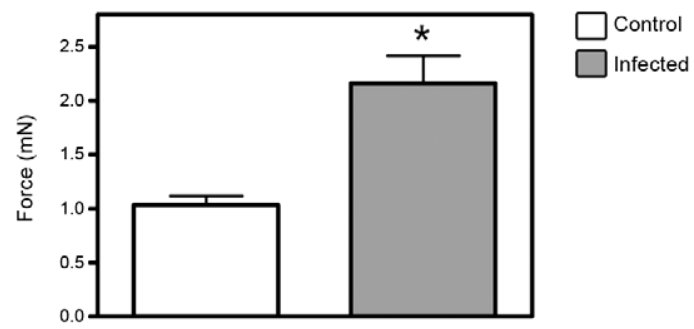

Fig. 2: contraction of aorta from control (white) and Schistosoma mansoni-infected (gray) mice in response to caffeine $32 \mathrm{mM}$. Experiments were performed in the presence of $N^{\omega}$-nitro-L-arginine $250 \mu \mathrm{M}$. Data are expressed as mean and standard error of the mean ( $\mathrm{n}=10$ rings). Asterisk means $\mathrm{p}<0.05$ (Student's $t$ test).

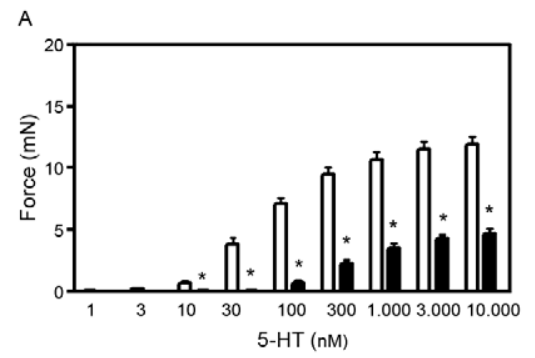

B

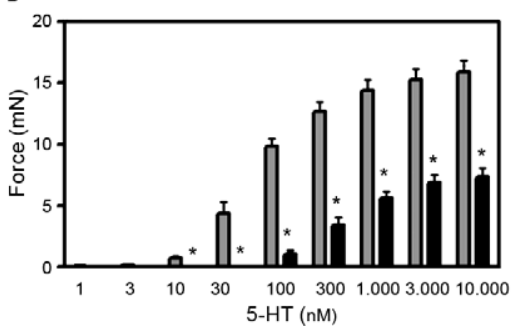

Fig. 3: 5-hydroxytryptamine (5-HT)-induced contraction of aorta from control (A) and Schistosoma mansoni-infected mice (B) in the absence (white or gray) and presence (black) of Rho kinase inhibitor $(\mathrm{Y}-27632,5 \mu \mathrm{M})$. Experiments were performed in the presence of $N^{\omega}$-nitro-L-arginine $250 \mu \mathrm{M}$. Data are expressed as the mean and standard error of the mean $(n=10$ rings). Asterisk means $\mathrm{p}<0.05$ (paired Student's $t$ test).

\section{DISCUSSION}

The present study shows that aorta from mice infected with $S$. mansoni develop an enhanced contraction in response to 5-HT, an important mediator involved in vascular contraction.

In murine aorta, 5-HT promotes vasoconstriction mainly through 5-HT ${ }_{2 \mathrm{~A}}$ receptors coupled to L-type calcium channels and phospholipase $\mathrm{C}$ pathways, among others (Mckune \& Watts 2001). For instance, this receptor is also linked to calcium mobilisation from sarcoplasmic reticulum through intracellular calcium channels known as ryanodine receptors (Low et al. 1997). As noted, 5-HT promoted a higher contraction in the aorta of infected animals than of controls. A similar effect was observed with caffeine, an activator of ryanodine receptors, suggesting that the increased response to 5-HT might be related to an enhanced calcium mobilisation from intracellular stores. Previous data have shown that both the vascular expression and activation of voltagedependent $\mathrm{L}$ type $\mathrm{Ca}^{2+}$ channels in the vasculature are enhanced in schistosomiasis (Silva et al. 2003, 2007). In addition, p38 mitogen-activated protein kinase (p38 MAPK) also contributes to 5-HT-induced contraction and the enzyme expression increases during schistosomiasis, at least in mice portal vein (Araujo et al. 2007).

\section{TABLE I}

Maximal effect of 5-hydroxytryptamine for contracting aorta from control and Schistosoma mansoni-infected mice in the absence or presence of Rho kinase inhibitor

\begin{tabular}{|c|c|c|}
\hline Group and treatment & $E_{\max }(\mathrm{mN})$ & $\mathrm{n}$ \\
\hline \multirow[t]{2}{*}{ Control } & $11.73 \pm 0.64$ & 10 \\
\hline & $4.88 \pm 0.33^{a}$ & 10 \\
\hline \multirow[t]{2}{*}{ Infected } & $15.75 \pm 0.96^{b}$ & 10 \\
\hline & $7.84 \pm 0.64^{a, b}$ & 10 \\
\hline
\end{tabular}

values are expressed as mean \pm standard error of the mean. $a: \mathrm{p}<0.05$ vs. respective condition without treatment (paired Student's $t$ test); $b: \mathrm{p}<0.05$ infected vs. control mice (Student's $t$ test); n: number of rings (see Materials and Methods).

\section{TABLE II}

Contraction induced by endothelin 1 in aorta from control and Schistosoma mansoni-infected mice in the absence or presence of Rho kinase inhibitor

\begin{tabular}{|c|c|c|}
\hline Group and treatment & \multirow{2}{*}{$\begin{array}{c}E_{\max }(\mathrm{mN}) \\
7.29 \pm 0.34\end{array}$} & \multirow{2}{*}{$\frac{\mathrm{n}}{10}$} \\
\hline Control & & \\
\hline$+\mathrm{Y}-27632$ & $0.01 \pm 0.02^{a}$ & 10 \\
\hline Infected & $7.02 \pm 0.42$ & 10 \\
\hline$+\mathrm{Y}-27632$ & $-0.02 \pm 0.03^{a}$ & 10 \\
\hline
\end{tabular}

values are expressed as mean \pm standard error of the mean. $a: \mathrm{p}<0.05$ vs. respective condition without treatment (paired Student's $t$ test). 
Therefore, we propose that the increased $\mathrm{Ca}^{2+}$ influx and mobilization, and possibly the increased activity of p38 MAPK, contribute to the enhancement of 5-HT-induced contraction during schistosomiasis.

The sensitivity of the contractile apparatus to cytosolic $\mathrm{Ca}^{2+}$ is also relevant and is affected by Rho kinasemediated signalling (Somlyo \& Somlyo 2003). Previous indirect data suggested that $\mathrm{Ca}^{2+}$ sensitivity of the aortic smooth muscle was not altered in schistosomiasis and therefore could not explain the enhanced contraction in response to the $\alpha_{1}$ adrenoceptor agonist noradrenaline (Silva et al. 2007) and 5-HT (present paper). Concordantly, we show here that the in vitro inhibition of Rho-kinase reduced the amplitude of the contraction in response to 5-HT similarly in both groups, discarding that the enhanced contraction might be related to an increased sensitivity of the contractile machinery, at least regarding Rho kinase signalling pathway.

Noradenaline increases aortic contraction (Silva et al. 2007) and we have shown that 5-HT has similar effects, suggesting non-specific vascular alteration. However, this does not seem likely since aortic contraction induced by $10 \mathrm{nM}$ ET-1 did not differ between groups. This finding is relevant since ET-1 can regulate pathophysiology of nonschistosomal portal hypertension (Ohara et al. 2001, de Toledo et al. 2009). In addition, Rho kinase inhibition reduced equally the contraction induced by ET-1 in both groups. Consequently, our data suggest once more that Rho kinase downstream signalling is not affected by the disease state.

Circulating cytokines in the vascular system may alter the phenotype of its myocytes and endothelial cells (Vila \& Salaices 2005, Sprague \& Khalil 2009). Therefore, enhancement of aortic contraction induced by 5 -HT and noradrenaline (Silva et al. 2007), as well as the enhanced contraction of portal vein to 5-HT (Silva et al. 1998, 2003), might reflect phenotypic changes induced by the diseaseassociated inflammation. For instance, p38 MAPK expression increases in schistosomiasis, which is involved in inflammation and also contributes to the enhanced portal vein contraction in response to 5-HT (Araujo et al. 2007). Consequently, immune-vascular interactions may occur in schistosomiasis, similar to the effects on non-vascular smooth muscle (Zhao et al. 2006).

The effects of cytokines on smooth muscle constriction have been observed and vary according to the receptor, tissue and intracellular signalling pathway involved (Vicaut et al. 1996, Adner et al. 2002, Hendriks-Balk et al. 2009). For instance, TNF up regulates $5-\mathrm{HT}_{2 \mathrm{~A}}$-mediated contraction (Adner et al. 2002), but not angiotensin II-mediated contraction (Vicaut et al. 1996). A previous report showed that the vascular contraction induced by ET-1 was unaffected by inflammation, while contraction due to 5-HT was enhanced (Hendriks-Balk et al. 2009). Accordingly, in our model the contraction induced by ET-1 was not affected. Of note, Nippostrongylus brasilienses infection up-regulates the expression of $5-\mathrm{HT}_{2 \mathrm{~A}}$ receptors in non-vascular smooth muscle and this effect is ascribed to IL-13 (Zhao et al. 2006). Concerning intracellular receptors, IL-4 and IL-13, cytokines involved in the pathophysiology of asthma and schistosomiasis, up- regulate the expression of ryanodine receptors in airway smooth muscle cells (Jude et al. 2008, Kellner et al. 2008). Therefore, these vascular alterations involving $5-\mathrm{HT}_{2 \mathrm{~A}}$ receptors and their signalling pathways could implicate 5-HT both in portal hypertension (Bosch et al. 1992, Kaumann \& Levy 2006) and secondary extra-portal vascular alterations occasionally observed in schistosomiasis as, for example, pulmonary hypertension (de Cleva et al. 2003, Franco-Paredes et al. 2007).

According to the occupation theory, in the analysis of a dose-response curve, the amplitude of the response depends on the number of receptors occupied by the agonist (reviewed in Kenakin 1993). As the maximal response to 5-HT was enhanced in the infected group, one possible explanation is an increase of $5-\mathrm{HT}_{2 \mathrm{~A}}$ receptors expression as already observed in other inflammationassociated conditions (Adner et al. 2002, Zhao et al. 2006, Hendriks-Balk et al. 2009). However, the maximal effect may also increase due to a raise of intrinsic efficacy of the agonist, which means the capacity of the agonist to initiate a stimulus (i.e., intracellular signalling activation) from one receptor (reviewed in Kenakin 1993). Therefore, further experiments that systematically investigate the expression of vascular receptors in schistosomiasis are required and may add to the knowledge of the pathobiology of schistosomiasis.

As a conclusion, our data suggest that an immunevascular interaction occurs in schistosomiasis altering vascular contraction outside the mesenteric portal system. More importantly, it affects distinct intracellular signalling involved in aorta contraction, in this case increasing 5- $\mathrm{HT}_{2 \mathrm{~A}}$ receptor signalling. Therefore, a possible immunevascular interaction, as described for other inflammatoryassociated conditions, may be the basis for some vascularrelated clinical alterations observed in the disease.

\section{ACKNOWLEDGEMENTS}

To Orlando da Rocha Moreira and José Ferreira Oliveira (UFRJ, Brazil), for technical assistance, and to the Laboratory of Malacology (Fiocruz, Rio de Janeiro, Brazil), for cercariae donation.

\section{REFERENCES}

Adner M, Rose AC, Zhang Y, Swärd K, Benson M, Uddman R, Shankley NP, Cardell L-O 2002. An assay to evaluate the long-term effects of inflammatory mediators on murine airway smooth muscle: evidence that TNF $\alpha$ up-regulates $5-\mathrm{HT}_{2 \mathrm{~A}}$-mediated contraction. Br J Pharmacol 137: 971-982.

Araujo FP, Quintas LEM, Noel F, Silva CLM 2007. Schistosoma mansoni infection enhances host portal vein contraction: role of potassium channels and p38 map kinase. Microbes Infect 9: 1020-1025.

Bosch J, Pizcueta P, Feu F, Fernández M, García-Pagán JC 1992. Pathophysiology of portal hypertension. Gastroenterol Clin North Am 21: 1-14.

Caldas IR, Campi-Azevedo AC, Oliveira LF, Silveira AM, Oliveira RC, Gazzinelli G 2008. Human schistosomiasis mansoni: immune responses during acute and chronic phases of the infection. Acta Trop 108: 109-117.

Cheever AW, Lenzi JA, Lenzi HL, Andrade ZA 2002. Experimental models of Schistosoma mansoni infection. Mem Inst Oswaldo Cruz 97: 917-940. 
Crosby A, Jones FM, Southwood M, Stewart S, Schermuly R, Butrous G, Dunne DW, Morrell NW 2010. Pulmonary vascular remodeling correlates with lung eggs and cytokines in murine schistosomiasis. Am J Respir Crit Care Med 181: 279-288.

Cutts L, Wilson RA 1997. The protein antigens secreted in vivo by adult male Schistosoma mansoni. Parasitology 114: 245-555.

de Cleva R, Herman P, Pugliese V, Zilberstein B, Saad WA, Rodrigues JJ, Laudanna AA 2003. Prevalence of pulmonary hypertension in patients with hepatosplenic mansonic schistosomiasisprospective study. Hepatogastroenterology 50: 2028-2030.

de Toledo CF, Carvente CT, Shigueoka DC, Borges DR 2009. Endothelial markers in schistosomiasis patients with and without portal hypertension. Dig Dis Sci 54: 1331-1336.

Eddahibi S, Guignabrt C, Barlier-Mur A-M, Dewachter L, Fadel E, Dartevelle P, Humbert M, Simonneau G, Hanoun N, Saurini F, Hamon M, Adnot S 2006. Cross talk between endothelial and smooth muscle cells in pulmonary hypertension. Critical role for serotonininduced smooth muscle hyperplasia. Circulation 113: 1857-1864.

Franco-Paredes C, Rouphael N, Méndez J, Folch E, Rodriguez-Morales AJ, Santos JI, Hurst JW 2007. Cardiac manifestations of parasitic infections. Part 3: pericardial and miscellaneous cardiopulmonary manifestations. Clin Cardiol 30: 277-280.

Hendriks-Balk MC, Tjon-Atsoi M, Hajji N, Alewijnse AE, Peters SLM 2009. LPS differentially affects vasoconstrictor responses: a potential role for RGS16? J Physiol Biochem 65: 71-84.

Iglarz M, Clozel M 2007. Mechanisms of ET-1-induced endothelial dysfunction. J Cardiovasc Pharmacol 50: 621-628.

Jude JA, Wylam ME, Walseth TF, Kannan MS 2008. Calcium signalling in airway smooth muscle. Proc Am Thorac Soc 5: 15-22.

Kaumann AJ, Levy FO 2006. 5-hydroxytryptamine receptors in the human cardiovascular system. Pharmacol Ther 111: 674-706.

Kellner J, Tantzscher J, Oelmez H, Edelmann M, Fischer R, Huber RM, Bergner A 2008. Mechanisms altering airway smooth muscle cell $\mathrm{Ca}^{2+}$ homeostasis in two asthma models. Respiration 76: 205-215.

Kenakin T 1993. Drug-receptor theory. In T Kenakin (ed.), Pharmacologic analysis of drug-receptor interaction, Raven Press, New York, p. 1-38.

Kolosionek E, Graham BB, Tuder R, Butrous G 2010. Pulmonary vascular disease associated with parasitic infection - the role of schistosomiasis. Clin Microbiol Infect 17: 15-24.

Lenzi HL, Romanha W de S, Zorzenon dos Santos RM, Rosas A, Mota EM, Manso PPA, Caputo LFG, Pelajo-Machado M 2006. Four whole-istic aspects of schistosome granuloma biology: fractal arrangement, internal regulation, autopoietic component and closure. Mem Inst Oswaldo Cruz 101 (Suppl. I): 219-231.
Low AM, Sormaz L, Kwan CY, Daniel EE 1997. Actions of 4-chloro3-ethyl phenol on internal $\mathrm{Ca}^{2+}$ stores in vascular smooth muscle and endothelial cells. Br J Pharmacol 122: 504-510.

Mckune CM, Watts SW 2001. Characterization of the serotonin receptor mediating contraction in the mouse thoracic aorta and signal pathway coupling. J Pharmacol Exp Ther 297: 88-95.

Ohara N, Futagawa S, Watanabe S, Fukasawa M, Takamori S 2001. Clinical investigation of endothelin-1 and nitric oxide in patients with portal hypertension focusing on plasma levels and immunohistological staining of liver tissue. Hepatol Res 21: 40-54.

Silva CLM, Gontijo LS, Noël F 2007. Noradrenaline-induced contraction of mice aorta is enhanced in schistosomiasis. Vasc Pharmacol 46: 122-128.

Silva CLM, Lenzi LH, Silva VF, Paulo FO, Noël F 2003. Cellular mechanisms involved in the increased contraction of portal veins from Schistosoma mansoni-infected mice. Parasitol Res 89: 16-22.

Silva CLM, Morel N, Lenzi HL, Noel F 1998. Increased reactivity to 5-hydroxytryptamine of portal veins from mice infected with Schistosoma mansoni. Comp Biochem Physiol A Mol Integr Physiol 120: 417-423.

Somlyo AP, Somlyo AV 2003. $\mathrm{Ca}^{2+}$ sensitivity of smooth muscle and nonmuscle myosin II: modulated by G proteins, kinases, and myosin phosphatase. Physiol Rev 83: 1325-1358.

Sprague AH, Khalil RA 2009. Inflammatory cytokines in vascular dysfunction and vascular disease. Biochem Pharmacol 78: 539-552.

Vicaut E, Rasetti C, Baudry N 1996. Effects of tumor necrosis factor and interleukin-1 on the constriction induced by angiotensin II in rat aorta. J Appl Physiol 80: 1891-1897.

Vila E, Salaices M 2005. Cytokines and vascular reactivity in resistance arteries. Am J Physiol Heart Circ Physiol 288: H1016-H1021.

Wilson RA, Coulson PS 1986. Schistosoma mansoni: dynamics of migration through the vascular system of the mouse. Parasitology 92: 83-100.

Wynn TA, Thompson RW, Cheever AW, Mentink-Kane MM 2004. Immunopathogenesis of schistosomiasis. Immunol Rev 201: 156-167.

Zhang H, Park Y, Wu J, Chen XP, Lee S, Yang J, Dellsperger KC, Zhang C 2009. Role of TNF- $\alpha$ in vascular dysfunction. Clin Sci (Lond) 116: 219-230.

Zhao A, Urban JF, Morimoto M, Elfrey JE, Madden KB, Finkelman FD, Shea-Donohue T 2006. Contribution of $5-\mathrm{HT}_{2 \mathrm{~A}}$ receptor in nematode infection-induced murine intestinal smooth muscle hypercontractility. Gastroenterology 131: 568-578.

Zhou Y, Dirksen WP, Zweier JL, Periasamy M 2004. Endothelin1-induced responses in isolated mouse vessels: the expression and function of receptor types. Am J Physiol Heart Circ Physiol 287: H573-H578. 